\title{
A escuta pedagógica à criança hospitalizada: discutindo o papel da educação no hospital
}

Rejane de S. Fontes

Universidade Federal Fluminense, Faculdade de Educação

\section{Introdução}

A identidade de ser criança é, muitas vezes, diluída numa situação de internação, em que a criança se vê numa realidade diferente da sua vida cotidiana. O papel de ser criança é sufocado pelas rotinas e práticas hospitalares que tratam a criança como paciente, como aquele que inspira e necessita de cuidados médicos, que precisa ficar imobilizado e que parece alheio aos acontecimentos ao seu redor. Na tentativa de compreender o resgate da subjetividade e sua contribuição para a saúde da criança hospitalizada, proponho a análise de situações pedagógicas enquanto interações sociais privilegiadas da criança nesse novo momento de sua vida.

Os estudos e pesquisas voltados para a análise da infância revelam que esse período da vida vai desde o nascimento até a puberdade. É a idade da meninice, porém vale ressaltar que considerar o grau de importância social atribuído a essa fase é algo recente na história ocidental.

Na sociedade medieval não havia valorização da infância, e a indiferença dessa época para com a crian- ça é muito significativa. A particularidade dos cuidados com o infante era negada, o que resultava na elevada taxa de mortalidade infantil. Ariès (1981) mostra-nos que o moderno sentimento familiar, caracterizado pela intensidade das relações afetivas entre pais e filhos, privacidade do lar e cuidados especiais com a infância, foi produzido ao longo dos anos pelas mudanças socioeconômicas instaladas nas sociedades industrializadas.

Todavia, é importante ressaltar que a história da infância no Brasil se confunde com a história do preconceito, da exploração e do abandono, pois desde o início houve a diferenciação entre as crianças segundo sua classe social, com direitos e lugares diversos no tecido social. Elegeram-se, assim, alguns poucos como portadores do "vir a ser" (grandes homens e grandes mulheres), enquanto tantos outros foram reduzidos à servidão, muitas vezes classificados como geneticamente doentes e, assim, socialmente incapazes.

Quando me propus realizar a pesquisa, procurei dar prosseguimento às reflexões que desenvolvi durante a graduação como bolsista de iniciação científi- 
ca pelo Programa Institutcional de Bolsas de Iniciação Científica (PIBIC) promovido pelo Conselho Nacional de Pesquisa (CNPq), ${ }^{1}$ quando minha preocupação central foi investigar a validade de um atendimento educacional em curto prazo realizado em hospitais. As preocupações que estiveram na origem desse projeto surgiram a partir dos altos índices de evasão ${ }^{2}$ e atraso escolar das crianças e adolescentes que permaneciam hospitalizados durante um determinado período de suas vidas. Foi pensando nesse universo de crianças e adolescentes que se encontra temporária ou permanentemente internado que dei prosseguimento aos estudos realizados entre 1995 e 1998, com vistas à implantação de um acompanhamento pedagógico-educacional na Enfermaria Pediátrica do Hospital Universitário Antônio Pedro (HUAP).

Para melhor situar a abordagem metodológica da pesquisa realizada, apresento brevemente suas características, começando pelo problema que instiga a investigação: quais as possibilidades e os limites de uma educação para a saúde com crianças, na faixa etária dos 7 aos 14 anos, de ambos os sexos, com possibilidades de deslocamento (sala de recreação), e que passam pelo processo de reinserção na Enfermaria Pediátrica do HUAP? Considero, para tanto, as formas de inserção dessas crianças no ambiente hospitalar (seja por meio do setor de emergência, do ambulatório para exame ou tratamento, ou ainda para intervenção cirúrgica), bem como o tempo e a freqüência dessas hospitalizações.

A pesquisa tinha como objetivo geral compreender como o conhecimento da vivência hospitalar e a apropriação dos sentidos expressos no ambiente refletem o papel da educação no desenvolvimento cognitivo, emocional e da saúde de crianças hospitalizadas na enfermarias pediátricas. E como objetivos específicos:

${ }^{1}$ Pesquisa desenvolvida com orientação das professoras Cristina Maria Carvalho Delou e Liliana Hochman Weller.

${ }^{2} \mathrm{Na}$ realidade as crianças não se evadem, elas são expulsas pelas adversidades impostas pelo sistema. a) Analisar, po intermédio de atividades pedagógicas, o papel do conhecimento, da emoção e da linguagem para a saúde da criança hospitalizada.

b) Descrever e analisar uma prática pedagógica em hospital como alternativa de atendimento educacional, apontando suas conquistas e dificuldades.

c) Refletir sobre a atuação do professor e os novos caminhos para a educação a partir do acompanhamento pedagógico em âmbito hospitalar.

Esses objetivos buscavam não só compreender a contribuição da educação, ao operar com processos de conhecimento afetivos e cognitivos no resgate da saúde da criança hospitalizada, como também definir o espaço de atuação do professor, muitas vezes confundido com o do psicólogo, na estrutura hospitalar.

O tema reveste-se de uma importância crucial nos dias atuais a partir da constatação de que sua análise se volta para as populações já sistematicamente excluídas, ${ }^{3}$ socioeconomicamente, do acesso a bens culturais e de saúde. A relevância deste estudo devese ao fato de se realizar em instituições hospitalares públicas que apresentam atendimento em enfermarias pediátricas. Entre elas, escolhi o HUAP, situado em Niterói (RJ), compromissado com a pesquisa e que atende a uma elevada parcela de nossa população historicamente desrespeitada em seus direitos, que tem na educação sua principal via de cidadania e esperança de ascensão social.

Desse modo, ao longo do presente artigo pretendo responder às seguintes questões:

a) É possível pensar o hospital como um espaço educacional para as crianças internadas em enfermarias pediátricas?

b) Pode a educação contribuir para a saúde da criança hospitalizada?

\footnotetext{
${ }^{3}$ Algumas crianças nem excluídas serão, porque não serão
} sequer incluídas, como, por exemplo, os bebês da Unidade de Terapia Intensiva (UTI) neonatal. 
c) Que formas de educar são possíveis num hospital?

d) Quais os limites e as possibilidades de atuação do professor nesse novo locus de atuação?

\section{A educação no hospital: pensando a formação e a prática de professores para atuação em hospitais}

O trabalho pedagógico em hospitais apresenta diversas interfaces de atuação e está na mira de diferentes olhares que o tentam compreender, explicar e construir um modelo que o possa enquadrar. No entanto, é preciso deixar claro que tanto a educação não é elemento exclusivo da escola quanto a saúde não é elemento exclusivo do hospital. O hospital é, inclusive, segundo definição do Ministério da Saúde, um centro de educação.

Hospital é a parte integrante de uma organização médica e social, cuja função básica consiste em proporcionar à população assistência médica integral, curativa e preventiva, sob quaisquer regimes de atendimento, inclusive o domiciliar, constituindo-se também em centro de educação, capacitação de recursos humanos e de pesquisas em saúde, bem como de encaminhamento de pacientes, cabendo-lhe supervisionar e orientar os estabelecimentos de saúde a ele vinculados tecnicamente. (Brasil, 1977, p. 3.929)

Refletir sobre a atuação de professores em hospitais tem sido uma questão bastante delicada na recente, mas já polêmica, discussão da prática pedagógica em enfermarias pediátricas.

A discussão começa entre duas correntes teóricas aparentemente opostas, mas que podem ser vistas como complementares. A primeira delas, talvez a mais difundida hoje no Brasil e com respaldo legal na Política Nacional de Educação Especial (Brasil, 1994) e seus desdobramentos (Diretrizes Nacionais para a Educação Especial na Educação Básica - Brasil, 2001) defende a prática pedagógica em classes hospitalares. São representantes dessa visão autores como Fonseca (2001, 2002), Ceccim (1997) e Ceccim e Fonse- ca (1999), que têm publicações nessa área de conhecimento.

Segundo a política do Ministério da Educação (MEC),

Classe hospitalar é um ambiente hospitalar que possibilita o atendimento educacional de crianças e jovens internados que necessitam de educação especial e que estejam em tratamento hospitalar. (Brasil, 1994, p. 20)

Essa corrente defende a presença de professores em hospitais para a escolarização das crianças e jovens internados segundo os moldes da escola regular, contribuindo para a diminuição do fracasso escolar e dos elevados índices de evasão e repetência que acometem freqüentemente essa clientela em nosso país.

Esse atendimento tem sido o modelo adotado desde 1950 pela primeira classe hospitalar do Brasil, a Classe Hospitalar Jesus, vinculada ao Hospital Municipal Jesus, no Rio de Janeiro, que foi uma das oitenta classes representadas no $1^{\circ}$ Encontro Nacional sobre Atendimento Escolar Hospitalar, acontecido em 2000 na Universidade do Estado do Rio de Janeiro, sob a coordenação geral da professora Dra. Eneida Simões da Fonseca.

A outra corrente de pensamento segue passos como os da professora Regina Taam, da Universidade Estadual de Maringá (UEM), que sugere a construção de uma prática pedagógica com características próprias do contexto, tempos e espaços hospitalares e não simplesmente transplantada da escola para o hospital. Segundo essa autora (Taam, 1997), faz-se necessária a construção de uma "pedagogia clínica", termo utilizado em seu artigo publicado na Revista Ciência Hoje. Com forte embasamento na teoria da emoção do médico francês Henri Wallon (1879-1962), Taam (2000) defende a idéia de que o conhecimento pode contribuir para o bem-estar físico, psíquico e emocional da criança enferma, mas não necessariamente o conhecimento curricular ensinado no espaço escolar. Segundo ela, o conhecimento escolar é o "efeito colateral" de uma ação que visa, primordialmente, à recuperação da saúde. $\mathrm{O}$ trabalho do professor é ensinar, não há dúvida, mas isso 
será feito tendo-se em vista o objetivo maior: a recuperação da saúde, pela qual trabalham todos os profissionais de um hospital.

Dessa forma, penso que tais correntes de pensamento, embora com especificidades próprias, tendem a se integrar na prática pedagógica hospitalar. A educação em hospitais oferece um amplo leque de possibilidades e de um acontecer múltiplo e diversificado que não deve ficar aprisionado a classificações ou enquadramentos.

Esta reflexão que ora apresento é fruto de seis anos de ensaios, experiências e aproximações desse tipo de trabalho com crianças internadas no HUAP, que possui especificidades próprias que serão, mais adiante, apresentadas.

\section{Conceituando idéias, discutindo palavras...}

Pensar sobre tais questões tem impelido-me como um veleiro que flutua ao sabor da correnteza epistemológica na tentativa de definir uma expressão que tenho lido em alguns trabalhos a respeito do tema, mas que até então nunca havia sido delimitada: pedagogia hospitalar. O que significa essa expressão? Será apenas um contraponto ao termo classe hospitalar? Qual a sua origem e o seu peso teórico?

Tais idéias levam-me a Clarice Lispector, quando diz...

Tenho de escrever. É tão perigoso. Quem tentou, sabe.

Perigoso de mexer no que está oculto - e o mundo não está à tona, está oculto em suas raízes submersas em profundidades do mar. Para escrever tenho que me colocar no vazio.

Neste vazio é que existo intuitivamente. Mas é um vazio terrivelmente perigoso: dele arranco sangue. Sou um escritor que tem medo da cilada das palavras que eu digo escondem outras - quais? Talvez as diga. Escrever é uma pedra lançada no poço fundo. (Lispector, 1978, p. 23)

As palavras traem-nos, aprisionam-nos, mas também nos libertam.

Tentar definir pedagogia hospitalar poderá nos trazer alguns esclarecimentos quanto à função e pos- síveis contribuições do professor no hospital. Poderá também nos ajudar a analisar sua formação e sua preparação para atuar com crianças nesse ambiente visivelmente diferente da sala de aula.

Podemos entender pedagogia hospitalar como uma proposta diferenciada da pedagogia tradicional, ${ }^{4}$ uma vez que se dá em âmbito hospitalar e que busca construir conhecimentos sobre esse novo contexto de aprendizagem que possam contribuir para o bemestar da criança enferma.

A contribuição das atividades pedagógicas para o bem-estar da criança enferma passa por duas vertentes de análise. A primeira aciona o lúdico como canal de comunicação com a criança hospitalizada, procurando fazê-la esquecer, durante alguns instantes, o ambiente agressivo no qual se encontra, resgatando sensações da infância vivida anteriormente à entrada no hospital. Essa vertente procura distrair a criança e, muitas vezes, o que consegue é irritá-la, e certamente não contribui para que ela reflita sobre a própria experiência e aprenda com ela. A segunda trabalha, ainda que de forma lúdica, a hospitalização como um campo de conhecimento a ser explorado. Ao conhecer e desmitificar o ambiente hospitalar, ressignificando suas práticas e rotinas como uma das propostas de atendimento pedagógico em hospital, o medo da criança, que paralisa as ações e cria resistência, tende a desaparecer, surgindo, em seu lugar, a intimidade com o espaço e a confiança naqueles que ali atuam.

Essa definição, no entanto, não exclui o conceito de classe hospitalar. Pelo contrário, a pedagogia hospitalar parece ser mais abrangente, pois não ex-

${ }^{4}$ Conforme definição em Luckesi (1994), a pedagogia tradicional baseia-se na transmissão, em forma de conteúdos, de conhecimentos historicamente acumulados pela humanidade e repassados, como dogmas, para as gerações mais novas. A metodologia baseia-se na exposição verbal, centrada na autoridade da figura do professor e em técnicas mnemônicas de assimilação do conteúdo, prejudicando, assim, a satisfação da curiosidade e das experiências infantis. 
clui a escolarização de crianças que se encontram internadas por várias semanas ou meses, mas a incorpora dentro de uma nova dinâmica educativa.

Após o impacto da hospitalização que Spitz (1965), Kamiyama (1972), Ariès (1977, 1982), Raimbault (1979), Weller (1979), Ajuriaguerra (1980), Mannoni (1983), Chiattone (1984), Angerami-Camon (1988), Guimarães (1988), Lenzi (1992), Lindquist (1993), Santa Roza (1993) e Ceccim e Carvalho (1997) já descreveram tão bem, a função do pedagogo/professor necessita ser de ressignificação daquele espaço para a criança enferma. Porém, nada impedirá que este seja, simultaneamente, um espaço educativo (no sentido amplo do termo), e mais tarde, para crianças que permaneçam por longo tempo, um espaço escolar, com a incorporação e acompanhamento dos conteúdos escolares da série em que a criança se encontra matriculada. A partir do contato com a professora dava escola, ou na dificuldade de estabelecer contato com a instituição, os conteúdos poderão ser elaborados pelo próprio professor, de acordo com o nível de conhecimento e aprendizagem identificado na criança hospitalizada.

Embora a grande maioria de professores que atuam com crianças em hospitais possua formação em nível de pós-graduação na área educacional, ${ }^{5}$ a formação em serviço é, indubitavelmente, o que tem assegurado um nível de qualidade crescente nessa modalidade de atendimento pedagógico, uma vez que não existe um curso, reconhecido pelo MEC, voltado para esse tipo de profissionalização. Mas apenas isso não basta. Precisamos garantir maiores e melhores condições de acompanhamento pedagógico-educacional à clientela infanto-juvenil internada, o que certamente virá com a formação específica de profissionais nessa área de conhecimento.

O que se verifica na prática é uma infinidade de patologias infanto-juvenis que coexistem num mesmo espaço de atendimento médico-hospitalar, e que, por suas especificidades, demandam tempos e espa-

\footnotetext{
${ }^{5}$ Cf. Fonseca, 2001.
}

ços diferenciados de atuação pedagógica. Paula (2002) identifica três grupos de crianças internadas em hospitais: crianças que são internadas com graves comprometimentos físicos, afetivos, sociais e cognitivos, e que permanecem durante muito tempo no hospital; crianças que apresentam comprometimentos moderados e que permanecem em média quinze dias nos hospitais; e crianças que são internadas com comprometimentos leves e que permanecem pouco tempo nos hospitais.

O ofício do professor no hospital apresenta diversas interfaces (política, pedagógica, psicológica, social, ideológica), mas nenhuma delas é tão constante quanto a da disponibilidade de estar com o outro e para o outro. Certamente, fica menos traumático enfrentar esse percurso quando não se está sozinho, podendo compartilhar com o outro a dor, por meio do diálogo e da escuta atenciosa.

Ceccim (1997) fala da escuta pedagógica para agenciar conexões, necessidades intelectuais, emoções e pensamentos, que entendo como pontos importantes para serem recuperados neste texto. Segundo este autor,

O termo escuta provém da psicanálise e diferencia-se da audição. Enquanto a audição se refere à apreensão/compreensão de vozes e sons audíveis, a escuta se refere à apreensão/compreensão de expectativas e sentidos, ouvindo através das palavras as lacunas do que é dito e os silêncios, ouvindo expressões e gestos, condutas e posturas. A escuta não se limita ao campo da fala ou do falado, [mais do que isso] busca perscrutar os mundos interpessoais que constituem nossa subjetividade para cartografar o movimento das forças de vida que engendram nossa singularidade. (Ceccim, 1997, p. 31)

Começamos a perceber nesse contexto intersubjetivo do hospital, em que se interpenetram os conceitos de educação e saúde, uma nova perspectiva de educação que fertilize a vida, pois o desejo de aprender/ conhecer engendra o desejo de viver no ser humano.

A escuta pedagógica diferencia-se das demais escutas realizadas pelo serviço social ou pela psico- 
logia no hospital, ao trazer a marca da construção do conhecimento sobre aquele espaço, aquela rotina, as informações médicas ou aquela doença, de forma lúdica e, ao mesmo tempo, didática. Na realidade, não é uma escuta sem eco. É uma escuta da qual brota o diálogo, que é a base de toda a educação.

Durante o tempo de hospitalização, o volume de informações a que as crianças e seus acompanhantes estão submetidos precisa ser trabalhado de modo pedagógico num contexto de atividades de socialização das crianças e de seus conhecimentos, sejam eles escolares, informais ou hospitalares (no caso das crianças reincidentes ou com maior tempo de internação). A criança aprende a criar mecanismos para minimizar a sua dor, e esses mecanismos podem ser socializados e até utilizados por outras crianças. Essa também é uma prática educativa, mediada pelo indivíduo mais experiente da cultura.

O importante é perceber a criança e seus familiares como seres pensantes que, quando chegam ao hospital, já trazem histórias de vida, conhecimentos prévios sobre o que é saúde, doença, e sobre sua ação nessa dinâmica. A atuação do professor deve proporcionar uma articulação significativa entre o saber do cotidiano do paciente e o saber científico do médico, sempre respeitando as diferenças que existem entre ambos os saberes.

\section{Refazendo a caminhada: análise do material bibliográfico levantado}

Entre os meses de janeiro e julho de 2002 fui consumida por uma aventura acadêmica que parecia não ter fim, na Biblioteca Central do campus do Gragoatá (BCG), na Biblioteca Central do HUAP, na Biblioteca da Escola de Enfermagem Professora Jane da Fonseca Proença da Universidade Federal Fluminense (UFF) e na Pró-Reitoria de Extensão da Universidade Federal Fluminense (PROEX). Nelas, empreendi o levantamento de trabalhos monográficos realizados até 2002, que abordassem a temática saúde e educação em enfermarias pediátricas em geral, e no HUAP, especificamente, a partir 1950, quando foi criado.
Pelo fato de o HUAP ser o campo de investigação desta pesquisa, concentrei a revisão bibliográfica nos trabalhos produzidos e catalogados nos espaços da UFF. Todavia, tenho certeza de que tal análise não esgota o tema, pois outros trabalhos poderão ter sido desenvolvidos, como teses de mestrado e doutorado realizados em outras universidades.

Foram levantados, em média, oitenta trabalhos por ano, desde a origem de suas produções, que se deu em períodos diferenciados, sobre os mais variados temas tratados segundo o enfoque de seis cursos de graduação e do curso de pós-graduação em educação da UFF, os quais foram selecionados cem trabalhos cujas análises apresento a seguir. A escolha dos cursos de graduação - a saber, serviço social, pedagogia, psicologia, história, medicina e enfermagem deve-se ao fato de apresentarem incursões nas áreas de educação, saúde e subjetividade, com investigações monográficas desenvolvidas no HUAP e na Enfermaria Pediátrica desse hospital.

Ao final da análise, pude constatar seguramente que esse tipo de atendimento pedagógico na Enfermaria Pediátrica do HUAP, como uma hipótese de intervenção da educação na saúde da criança hospitalizada, não foi registrado de forma sistematizada em trabalhos de tese, dissertação ou trabalhos de conclusão de curso catalogados nas bibliotecas pesquisadas, salvo referência ao estudo desenvolvido por mim como bolsista de iniciação científica (Fontes, 1998) e que frutificou na monografia de graduação, intitulada Classe hospitalar: a validade de uma alternativa educacional a curto prazo. ${ }^{6}$

Alguns questionamentos surgem diante de tais informações que nos deixam perplexos: por que o hospital nunca foi um campo de estágio oficial ou de pesquisa e prática pedagógica para os estudantes do curso de pedagogia, se é um hospital universitário e, por definição, um espaço de pesquisa? Por que algumas pesquisas morrem quando seus mentores se afas-

\footnotetext{
${ }^{6}$ A monografia de graduação foi orientada pela professora
} Cristina Maria Carvalho Delou. 
tam delas? Essas perguntas brotam impregnadas pela minha experiência pessoal; ao me desligar da pesquisa no HUAP, em 1998, não encontrei acadêmicos e professores orientadores que se interessassem em dar continuidade ao trabalho e à pesquisa que vinha sendo desenvolvida naquele espaço.

Além disso, essas perguntas reportam-nos ao distanciamento existente entre a Faculdade de Educação e a Escola de Medicina da UFF, enquanto campos férteis de pesquisa, produção e troca de conhecimentos, bem como à ausência do próprio tema saúde e educação entre as disciplinas da grade curricular do programa de graduação do curso de pedagogia, até 1998.

Enfim, todos os dados arrolados até aqui apontam para uma possível resposta, entre muitas que poderíamos encontrar: a atuação do professor e o desenvolvimento de um trabalho educacional na Enfermaria Pediátrica do HUAP constituem uma atividade historicamente inédita naquele campo de pesquisa, e precisou desbravar um caminho de interlocução entre os que historicamente só cuidaram do corpo e os que só cuidaram da mente. ${ }^{7}$

\section{A constituição do sujeito por meio da linguagem e da afetividade: um diálogo entre as teorias de Wallon e Vygotsky}

Ao nascer, o bebê é entregue a um mundo estranho e completamente desestruturado, recebendo um choque biopsicossocial profundo a partir do qual buscará formas para se harmonizar com o meio circundante. Do confronto entre o que o bebê traz como ser biológico e aquilo que se origina do bombardeio das experiências ambientais, ou seja, do conjunto constituído pelo inato e o adquirido, surgirá essa multiplicidade única de um ser epistemológico chamado homem.

$\mathrm{Na}$ tentativa de desvendar esse mistério chamado homem, diversos cientistas, entre eles médicos psi-

7 Buscando contribuir para tal diálogo, pretendo, mais adiante, ampliar essa revisão temática e transformá-la em outro artigo. quiatras, psicólogos e lingüistas, aventuraram-se na tarefa de compreender o funcionamento da mente e a constituição da subjetividade humana. Embora muito se tenha avançado na direção de entender a constituição subjetiva do ser humano, ainda há muito a discutir sobre o modo como ele constrói seu conhecimento.

Em busca dessa árdua tarefa, vimos despontar no início do século XX dois autores que trouxeram contribuições bastante originais para a compreensão da constituição do sujeito epistêmico e sua compreensão da realidade social; e, como não poderia deixar de ser, suas idéias encontraram ressonância no meio educacional. São eles o médico francês Henri Wallon (1879-1962) e o filólogo e psicólogo russo Lev Semenovich Vygotsky (1896-1934), dois contemporâneos na virada do século passado, cujas idéias, só tardiamente difundidas, permanecem vigorosas na tentativa de compreender o que é ainda um dos maiores mistérios da humanidade: o funcionamento da mente humana.

Wallon (1941) admite o organismo como primeira condição do pensamento; afinal, toda função psíquica supõe um equipamento orgânico. Todavia, o próprio autor adverte-nos que isso não é suficiente, uma vez que o objeto do pensamento vem do meio no qual o indivíduo se encontra inserido.

Wallon tomou os rumos da educação e dirigiu-se aos problemas concretos, do homem concreto, entendido na sua totalidade corpo-mente, ou, para nos colocarmos na perspectiva walloniana, inteligênciaemoção-movimento.

A fecundidade das contribuições da psicologia genética de Wallon para a educação deve-se à perspectiva global pela qual enfoca o desenvolvimento infantil, e também à atitude teórica que adota.

Para Wallon (1941), o desenvolvimento da pessoa assemelha-se a uma construção progressiva em que se sucedem fases com predominância alternadamente afetiva e cognitiva. Não há dúvida de que na teoria walloniana a emoção é a base da inteligência, seu primeiro suporte e seu vínculo com o social. Ainda latente durante o primeiro ano de vida do bebê, em que predominam as atividades puramente afetivas, a 
inteligência tende a diferenciar-se e a impulsionar a criança na exploração de seu ambiente.

A atividade emocional é uma das mais complexas características do ser humano, pois é simultaneamente biológica e social, e é por intermédio dela que se realiza a transição do biológico ao cognitivo, por meio da interação sociocultural. Sua natureza contraditória surge do fato de participar de dois mundos (o biológico e o social) e de fazer a transição entre eles na dimensão psicológica da constituição do sujeito.

A emoção possui aspecto contagiante, permeando todas as interações sociais do ser humano. A importância de resgatar-se no presente estudo esse aspecto da emoção da teoria de Wallon deve-se ao fato de que, na investigação junto a crianças hospitalizadas, o termômetro emocional é mais intenso do que numa situação cotidiana, o que tende a interferir, a priori, em sua construção do conhecimento, em sua compreensão da realidade. A acuidade de percepção do real fica diminuída pelas próprias manifestações viscerais e musculares de uma tensão emocional.

A maior contribuição de Vygotsky para a educação nasce de seu esforço de tentar compreender a relação entre o aprendizado e o desenvolvimento em crianças em idade escolar. Essa abordagem nos será muito importante na análise dos dados desta investigação.

É no brinquedo e no faz-de-conta que a criança pode imitar uma variedade de ações que estão muito além de seus limites de compreensão e de suas próprias capacidades. $\mathrm{O}$ brinquedo surge na vida da criança juntamente com sua capacidade de imaginar, de transcender o real e construir um mundo simbolicamente possível. O brinquedo, na realidade, surge da necessidade e do desejo frustrado da criança de realizar algo que concretamente ela não pode, naquele momento. Esse mundo de desejos realizáveis que desencadeia um novo comportamento na criança é o que chamamos de brinquedo.

Vygotsky (2000b) ressaltou a enorme influência que o brinquedo exerce no desenvolvimento da criança. É com o brinquedo que a criança aprende a agir numa esfera cognitiva descolada da realidade imediata e passa a dominar os objetos independentemente daquilo que vê, contextualizando-os e ressignificando-os.

Vygotsky desenvolveu também uma das mais originais e brilhantes teorias acerca da linguagem como suporte e expressão do pensamento humano, utilizando-se da analogia com o instrumento, enquanto ferramenta concreta do pensamento humano. Segundo ele, o material básico do pensamento é a linguagem. Enquanto o instrumento é visto como um meio externo, o signo é concebido como um meio interno do desenvolvimento humano.

Para Wallon e Vygotsky, a aprendizagem está pautada na interação do indivíduo com o meio no qual está inserido. Vygotsky, de modo particular, enfatizou o papel da cultura na história pessoal, e o da linguagem na construção do conhecimento, discutindo a criança não apenas como construtora individual do conhecimento, mas vendo-a em interação com elementos de sua cultura. A linguagem é o sistema simbólico básico de todos os grupos humanos. A questão do desenvolvimento da linguagem e suas relações com o pensamento é um dos temas centrais na investigação de Vygotsky. A linguagem, que é simultaneamente individual e social, modifica e constrói conhecimentos e sujeitos.

Podemos concluir que tanto em Wallon (1971, 1975) quanto em Vygotsky (2000a, 2000c) a individuação apresenta-se como um processo mediado pela socialização, seja afetiva ou lingüisticamente. A identidade de indivíduos socializados forma-se simultaneamente no meio do entendimento lingüístico com outros e no meio do entendimento intra-subjetivohistórico-vital consigo mesmo. A individualidade forma-se, assim, em condições de reconhecimento intersubjetivo, e este só se efetiva pelo afeto.

Quando privadas da interação com seu grupo social, crianças portadoras, ainda que momentaneamente, de necessidades especiais (como é o caso das crianças hospitalizadas) são impedidas de ter acesso à construção de conhecimentos e de constituir sua própria subjetividade. A criança hospitalizada, quando privada de interações sociais de boa qualidade, cujo 
teor lhe proporcione outras formas de compreender a vida, está sendo atomizada em sua oportunidade de aprender e, conseqüentemente, de se desenvolver.

Enfim, a constituição do eu é um processo condenado ao inacabamento, que persistirá eternamente dentro de cada um de nós.

A escolha desses dois autores para fundamentar este estudo não é ocasional. As similaridades que complementam as obras de Wallon e Vygotsky ajudamme a compreender o desafio de uma educação que resgate a saúde da criança hospitalizada, situada e datada. $\mathrm{O}$ aspecto materialista dialético da constituição do sujeito histórico talvez seja o ponto central que mais aproxima esses autores em seus estudos.

\section{Metodologia científica: o pesquisador $\mathrm{e} o$ ato de pesquisar}

Nessa linha de entendimento, uma investigação que busque compreender o papel da educação na saúde da criança hospitalizada tem como ação principal a observação participante, cujas informações coletadas receberiam um tratamento qualitativo à luz da compreensão do pesquisador, envolvendo ainda a dimensão socioistórica, na qual pesquisador e sujeitos da pesquisa encontram-se dialeticamente inseridos.

Segundo Thiollent (1985), ao empreender uma pesquisa de caráter qualitativo, o pesquisador deve estar ciente de que o processo reflexivo e de construção do conhecimento se encontra centrado no sujeito da pesquisa (pesquisador ou pesquisado), entendido enquanto sua postura interpretativa e compreensiva acerca do objeto (ou sujeito de estudo) e das condições sociais da realidade que o circunda, e não com base somente em dados quantitativos, como se eles existissem independentemente do olhar do pesquisador e do sujeito pesquisado. Há, durante o processo, um acompanhamento das decisões, das ações e de toda a atividade intencional dos atores da situação. A pesquisa não se limita a uma forma de ação (risco de ativismo); pretende aumentar o conhecimento dos pesquisadores e o conhecimento ou o "nível de consciência" das pessoas e grupos considerados.
No plano individual, o pesquisador logo defrontase com a sua implicação psicoafetiva (Barbier, 1985), pois na pesquisa qualitativa o objeto de investigação freqüentemente questiona os fundamentos da personalidade profunda, principalmente quando a dialética vida/ morte torna-se a essência do trabalho psicopedagógico, como naquele desenvolvido dentro de um hospital. A implicação do pesquisador é parte inerente e dinâmica do processo de construção do conhecimento. Assim, onde houver ciência humana haverá necessariamente a colagem da implicação do pesquisador em sua multidimensionalidade simbólica e imaginária.

O pesquisador desempenha, então, seu papel profissional numa dialética que articula constantemente a implicação e o distanciamento, a afetividade e a racionalidade, o simbólico e o imaginário, a mediação e o desafio, a autoformação e a heteroformação, a ciência e arte. (Barbier, 2002, p. 18)

Mas como estranhar aquilo que the parece entranhado? Como o pesquisador pode conseguir distanciar-se do senso comum, uma vez que aquilo que estuda corre o risco de tornar-se familiar, ${ }^{8}$ e, ao mesmo tempo, controlar suas inclinações pessoais, seus preconceitos que interferem em sua análise? Fazenda (1989, p. 43) sugere “o 'estranhamento', uma atitude de policiamento contínuo do pesquisador para transformar o familiar em estranho".

Numa abordagem científica do tipo da que ocorre em ciências humanas, como é o caso da educação, em que o observador é da mesma natureza do observado, deve haver um cuidado redobrado por parte do pesquisador, a fim de delimitar claramente o que foi constatado e o que foi inferido em suas observações de campo.

$\mathrm{Na}$ área educacional, em diversos países existe uma tradição de pesquisa participativa em matéria de

\footnotetext{
${ }^{8}$ Embora o hospital não seja um espaço familiar para o pro-
} fessor, isso pode ocorrer quando se fica durante algum tempo imerso numa dada realidade. 
formação de adultos, educação popular, formação sindical e outras áreas educacionais de caráter alternativo. No Brasil, essa prática começou a ser difundida recentemente e já conta com um crescente número de estudos sociais publicados nessa abordagem metodológica, considerada uma das mais autênticas expressões da filosofia materialista dialética na investigação científica.

A abordagem metodológica mais indicada para esta investigação é a do tipo qualitativa. Com o objetivo de capturar as mudanças em processo, a presente pesquisa utilizou técnicas como a observação participante, com o intuito de compreender as relações de convivência no âmbito hospitalar, entrevistas abertas, depoimentos, vivências (em que o pesquisador pode estruturar sua investigação científica com pretensa aproximação da verdade), estudo de documentos e textos impressos e eletrônicos, ${ }^{9}$ histórico da instituição, diário de bordo, análise de conteúdo e técnicas bibliográficas, uma vez que o embasamento teórico relativamente grande constitui-se no alicerce para a construção da subjetividade do pesquisador.

Barbier (2002, p. 141) apresenta-nos a escuta sensível como método de investigação científica a ser perseguido nesse tipo de estudo. Torna-se fundamental lembrar que "o homem permanecerá, para sempre, dividido entre o silêncio e a palavra", onde somente a escuta sensível do pesquisador poderá penetrar e captar o(s) significado(s) do não-dito.

A pesquisa qualitativa em educação enfatiza o processo, aquilo que está ocorrendo, e não o produto ou os resultados finais. Uma outra característica interessante desse tipo de abordagem é que a pesquisa refaz-se constantemente no próprio processo de investigação. Para isso, utiliza-se de um planejamento flexível, em que os focos de investigação vão sendo revistos, as técnicas de coletas, modificadas, os instrumentos, reformulados, e os fundamentos teóricos, repensados.

\footnotetext{
${ }^{9}$ Segundo a classificação contida nas normas bibliográficas
} da Associação Brasileira de Normas Técnicas (ABNT).
A observação participante foi eleita o principal procedimento metodológico nesta pesquisa. Por meio dela o pesquisador procura revelar a multiplicidade de dimensões presentes numa determinada situação, focalizando-as como um todo, como, por exemplo, as interações que ocorriam na sala de recreação do HUAP.

Lüdke e André (1986) elencam algumas características principais dos estudos qualitativos. Os estudos enfatizam a interpretação em contexto, ou seja, para uma apreensão mais completa do objeto é preciso levar em consideração o contexto em que ele se situa. $\mathrm{O}$ estudo qualitativo usa uma grande variedade de fontes de informação. Ao desenvolvê-lo, o investigador deve recorrer a diferentes técnicas de coleta de informações, como entrevistas com diferentes informantes, análise de documentos de diferentes fontes, observação de diferentes situações em momentos diferenciados etc.

As autoras sugerem ainda que o pesquisador deve ter consciência de que ele é o principal instrumento de coleta de informações; por isso, é fundamental que domine suficientemente o assunto a ser focalizado, funcionando como verdadeiro filtro de constatações. No estudo também não há hipóteses anteriores à entrada em campo, mas sim questões norteadoras, uma vez que o pesquisador não sabe o que irá encontrar no fluxo dos acontecimentos.

De acordo com Bogdan e Biklen (1994), o plano geral de um estudo pode ser representado por um funil. Os investigadores começam pela recolha de informações, revendo-as e explorando-as, e vão tomando decisões acerca do objetivo do trabalho.

Lüdke e André (1986), com base em estudos desenvolvidos por Nisbet e Watt, caracterizam o desenvolvimento do estudo qualitativo em três fases: a exploratória, a de delimitação do estudo e a da análise sistemática.

\section{A fase exploratória:}

É o momento de estabelecer contatos iniciais para a entrada em campo, de localizar os informantes e as fontes de dados necessárias para o estudo. 
2. A fase de delimitação do estudo:

Corresponde à coleta sistemática de informações, em que o pesquisador utiliza-se de instrumentos mais ou menos variados. A importância de delimitar os focos de investigação decorre do fato de que nunca será possível explorar todos os ângulos do fenômeno estudado.

3. A fase da análise sistemática:

Já na fase exploratória do estudo surge a necessidade de juntar a informação, analisá-la e torná-la disponível aos informantes para que manifestem suas reações sobre a relevância e a acuidade do que é relatado.

De acordo com as características apresentadas na pesquisa realizada, podemos classificá-la como estudo observacional. Nessa categoria, a técnica de coleta de informações em destaque é a observação participante. Agora não é a organização como um todo o que interessa, senão uma parte dela - no caso em tela, a dinâmica da sala de recreação da Enfermaria Pediátrica do HUAP.

Em se tratando de crianças hospitalizadas, a preocupação com a questão ética torna-se ainda maior. Além do consentimento dos pais, o pesquisador deverá ter o cuidado de garantir a adesão das crianças à sua pesquisa, pois

\footnotetext{
[...] a ética é entendida em termos de sua permanente obrigação com as pessoas que tocaram suas vidas no curso de viver a vida de pesquisador qualitativo.[...] Desenvolve-se uma relação de intimidade que muitas vezes se desdobra em envolvimentos emocionais do pesquisador com o sujeito por presenciar e participar em aspectos íntimos e às vezes dolorosos da vida dos sujeitos. (Monteiro, 1998, p. 19)
}

Para ajustar melhor o foco de investigação, utilizei o estudo observacional segundo propõem Bogdan e Biklen:

Neste tipo de estudos, a melhor técnica de recolha de dados consiste na observação participante e o foco do estu- do centra-se numa organização particular (escola, centro de reabilitação) ou nalgum aspecto particular dessa organização. (1994, p. 90)

Como instrumento de pesquisa, optei pela observação que, segundo Lüdke e André (1986), representa, junto com a entrevista não-estruturada, caracterizada pela não-diretividade, um dos instrumentos básicos para a coleta de informações dentro da abordagem qualitativa de pesquisa.

Outro instrumento metodológico de fundamental importância, que funciona como um registro de memória do pesquisador, refere-se ao diário de campo. Por meio desse procedimento, que consiste no registro escrito das ações vivenciadas e intenções captadas no cotidiano do espaço investigativo, o pesquisador possui um arquivo quase fidedigno de informações que o auxiliarão na análise dos acontecimentos que atravessam o trabalho de pesquisa em campo.

A pesquisa de campo deu-se integralmente na Enfermaria Pediátrica do HUAP. A escolha foi intencional, pois é o único local dentro da estrutura hospitalar que reúne o maior número de crianças internadas durante o tempo médio de quinze dias, além de oferecer condições físicas apropriadas para o desenvolvimento do trabalho pedagógico em questão.

Optei por classificar os temas que emergiram das associações livres, das cenas e da entrevistas, agrupando-os e reagrupando-os posteriormente de forma sucessiva, até formar os grandes grupos temáticos, as denominadas categorias.

Analisar é a prática de interpretar sob a luz da teoria.

Nesse ponto apóio-me em Triviños (1987, p. 162), que ressalta a interação dos materiais em relação ao conteúdo manifesto e ao conteúdo latente. O primeiro orienta para algumas conclusões apoiadas em dados quantitativos, porém o segundo possibilita a descoberta de tendências e características de fenômenos sociais, fornecendo uma análise dinâmica e desvendando pressupostos, especialmente os de natureza cultural, como, por exemplo, os valores próprios dos indivíduos. 


\section{Conhecendo o universo da pesquisa}

O período de internação médio na Enfermaria Pediátrica do HUAP é de quinze dias (na maioria das vezes, causada por doença respiratória), e há grande reincidência de crianças com leucemia ${ }^{10}$ (devido ao tratamento quimioterápico exigido pela doença e seus efeitos colaterais) e síndrome nefrótica ${ }^{11}$ (por causa do tratamento de hemodiálise e suas complicações). Pacientes com leucemia e síndrome nefrótica sofrem

${ }^{10}$ Leucemia: grupo de doenças degenerativas dos tecidos responsáveis pela formação de células sanguíneas na medula. A leucemia é caracterizada pela produção crescente de células brancas no sangue. A medula normal é progressivamente substituída por células malignas e a produção de outros elementos, como células vermelhas e plaquetas, é reduzida. Contudo, a leucemia não se relaciona exclusivamente com o crescente número de células brancas; as células podem ser normais em número, mas estruturalmente defeituosas, ou podem até ser normais tanto em número quanto em estrutura. A leucemia aguda é caracterizada pela incapacidade de amadurecimento das células brancas, que se proliferam na medula óssea e se acumulam no sangue. Inicialmente, os sintomas são parecidos com os de uma gripe, podendo ocorrer hemorragias nas gengivas e no nariz. As leucemias crônicas têm como característica a incapacidade de remoção de células brancas da circulação, o que faz com que estas fiquem acumuladas. Dentre seus sintomas estão cansaço, perda de peso, dificuldade de respirar, perda de apetite, desconforto abdominal e equimoses. Existem alguns tipos de leucemia, tanto agudas quanto crônicas, que são classificadas de acordo com sua origem, com as anormalidades celulares e com o desenvolvimento da doença. Nas leucemias agudas, a expectativa de vida é geralmente pequena quando não há tratamento; nas leucemias crônicas, a expectativa de vida pode ser de muitos anos (Nova Enciclopédia Ilustrada Folha, 1996, p. 562).

${ }^{11}$ Síndrome nefrótica: conjunto de sinais e sintomas que se desenvolvem conjuntamente e que indicam a existência de uma doença provocada pelo não-funcionamento ou funcionamento debilitado dos nefros, que são unidades filtradoras da urina, estimados em cerca de um milhão na estrutura de cada rim (Soares, 1982, p. 108). reinternações porque as doença são crônicas, exigem internação para tratamento, e esse pode causar descompensação no organismo da criança que precisa se internar. Casos como esses não são incomuns na Enfermaria Pediátrica do HUAP: entre os doze leitos destinados a crianças em idade escolar e pré-escolar, pelo menos dois, a cada novo ciclo de internação, são ocupados por crianças que estão voltando ao hospital.

Em sete meses de imersão no campo (janeiro a julho de 2002), tive contato com 32 crianças (16 meninos e 16 meninas). As atividades aconteciam duas vezes na semana, com duração média de três horas diárias, pela manhã, totalizando 56 encontros e 168 horas de atividades pedagógicas com as crianças internadas.

A observação do grupo de crianças no campo da pesquisa deu-se em dois momentos. Numa primeira fase, que chamarei, de acordo com Lüdke e André (1986), de exploratória, desenvolvi atividades pedagógicas com todas as crianças e adolescentes que podiam se locomover até a sala de recreação, a fim entender suas reações durante a internação e a contribuição do trabalho pedagógico ao seu bem-estar físico e psicológico.

A linguagem verbal e não-verbal (gestos, olhares, desenhos) foram o meio privilegiado de observar a produção de conhecimentos pelo sujeito, uma vez que constituem sinais exteriores que acompanham as atividades das crianças.

Numa segunda fase, que chamarei de focal, correspondendo à fase de delimitação do estudo, conforme propõem Lüdke e André (1986), embora continuasse trabalhando pedagogicamente com todas as crianças que se dirigiam à sala de recreação, centreime na observação dos sujeitos que estavam vivendo sua segunda internação e nos sujeitos que contavam com mais de trinta dias de hospitalização, a fim de observar suas reações ao processo vivenciado e ao trabalho pedagógico desenvolvido. Nesse segundo momento foram realizadas atividades pedagógicas com os sujeitos, individual ou coletivamente, a fim de criar um ambiente no qual os objetivos da pesquisa pudessem ser desenhados. 
O primeiro momento da segunda fase de intervenção pedagógica dava-se em grupos de crianças hospitalizadas, que chamei de grupos de interação, os quais não se enquadraram por classificações homogêneas, dada a própria realidade dinâmica da sala de recreação, que apresentava um fluxo constante de entrada e saída de adultos e crianças pertencentes a diferentes faixas etárias. Desse modo, o conceito de grupo tratado aqui é o proposto por Wallon (1975), que considera o grupo como uma "reunião de indivíduos tendo entre si relações que notificam a cada um o seu papel ou o seu lugar dentro do conjunto" (p. 167). Para Wallon, o grupo é indispensável à criança, não somente para sua aprendizagem social, mas também para o desenvolvimento da sua personalidade e da consciência de si e dos outros.

As atividades pedagógicas em grupo aconteciam duas vezes por semana, na sala de recreação. Participavam dessas atividades crianças compreendidas na faixa etária dos três aos quatorze anos, embora na seleção dos sujeitos focais tenha sido utilizado o critério de escolha de crianças que se encontravam na faixa etária escolar obrigatória, ou seja, dos sete aos quatorze anos.

O critério de escolha das atividades levou em consideração os seguintes aspectos: adequação à faixa etária, exigência de diferentes níveis de organização mental, atenção, respeito às regras, convívio social, conhecimento da rotina hospitalar, conhecimento de sua doença e de seu corpo, e expressão de seus pensamentos e sentimentos através da linguagem oral, gráfica e corporal.

Como o tempo de permanência das crianças no hospital era restrito, todas as atividades pedagógicas desenvolvidas tinham início, meio e fim dentro de um curto período de tempo, aproveitando-se, para tanto, todas as oportunidades de produção de novos conhecimentos e reconhecimento de antigos conceitos já adquiridos pelas crianças, sempre tomadas como atores sociais no decorrer de todo o processo de pesquisa.

Os critérios utilizados para a seleção dos sujeitos da investigação foram os seguintes:
1. Reincidentes, cuja primeira e demais internações na Enfermaria Pediátrica do HUAP tivessem se dado no período de janeiro a julho de 2002.

2. Não-reincidentes com tempo de internação prolongado (acima de 30 dias).

3. Condições físicas e psíquicas para participarem das atividades na sala de recreação da Enfermaria Pediátrica do HUAP.

Do grupo de 32 (trinta e duas) crianças e adolescentes hospitalizados na fase exploratória deste estudo, seis crianças (três meninos e três meninas) vivenciaram reinternações, sendo três delas reincidentes algumas vezes. Desse grupo, foram selecionadas 3 (três) crianças (dois meninos e uma menina) que se enquadravam nos critérios acima descritos.

Algumas categorias de análise foram priorizadas, buscando descrever fenômenos sociais humanos numa situação atípica na vida de uma criança: a hospitalização.

Entendo interação social como as relações de troca que se dão entre o sujeito e seu meio social. Quando a criança começa a interagir com seus pares, além de atuar e modificar o universo social (os outros) ela modifica seu próprio eu na tentativa de compreender a realidade que a cerca.

As interações observadas foram classificadas em três tipos:

a) a interação criança/criança;

b) a interação criança/adulto (acompanhantes/profissionais);

c) a interação criança/meio (rotina).

Essas interações manifestaram-se por meio de eixos de análise específicos, que busquei compreender através das seguintes categorias:

- Linguagem (significado e sentido) É por meio da linguagem que os sujeitos se constituem, incorporam conhecimentos sociais e afetivos e interagem com o mundo social que 
os cerca. Tanto para Wallon quanto para Vygotsky são a cultura e a linguagem que fornecem ao pensamento os instrumentos para sua evolução.

- Brinquedo e jogo (Zona de Desenvolvimento Proximal - ZDP)

É no brinquedo e no faz-de-conta que a criança pode imitar uma variedade de ações que estão muito além de seus limites de compreensão e de suas próprias capacidades. É a partir dessas atividades lúdicas que surge uma interpretação mais complexa da realidade, quando então a imitação começa dar origem à representação.

- Emoção (subjetividade e consciência) Para Wallon, ao permitir o acesso à linguagem, a emoção está na origem da atividade intelectual e da constituição da subjetividade. A emoção constitui uma etapa anterior à linguagem e está na base da representação. Pelas interações sociais que propiciam, as emoções possibilitam o acesso ao universo simbólico da cultura, o que leva ao progresso da vida mental. Mas, ao mesmo tempo em que se desenvolve, a razão estabelece com a emoção uma relação de filiação e de oposição, fazendo com que uma reflexão sobre as causas de uma crise emocional possibilite sua redução.

- Conhecimento (aprendizado e desenvolvimento através de construções partilhadas)

Tanto para Wallon quanto para Vygotsky a aprendizagem está pautada na interação do indivíduo com o meio no qual está inserido. Vygotsky considera que o desenvolvimento dos conceitos espontâneos (oriundos da experiência) e dos conceitos não-espontâneos (científicos) se relacionam e se influenciam mutuamente; e, embora seguindo caminhos diferentes desde o início, tendem a se encontrar no final. Poderíamos interpretar os conceitos espontâneos da criança em situação hospitalar como os conceitos oriundos do senso comum, e os conceitos científicos como aqueles de domínio do discurso médico.
A relação com a escolarização também é um fator importante para ser analisado neste trabalho, pois denota o grau de implicação da internação hospitalar com a evasão e repetência das crianças hospitalizadas, bem como a referência à escola como um lugar saudável.

\section{Era uma vez: escutando as histórias que os sujeitos nos contam em silêncio, em gestos e, às vezes, também em palavras}

A análise que será apresentada é resultado de uma triangulação de informações oriundas das observações registradas em diário de bordo, dos diálogos gravados em fitas cassetes e das produções gráficas dos sujeitos em estudo. O objetivo do uso desses recursos metodológicos era acompanhar as pequenas mudanças no comportamento da criança hospitalizada, desde a entrada até a alta médica, passando pelas reinternações, quando houvesse.

O silêncio é algo tão comum na Enfermaria Pediátrica quanto o choro e o grito de bebês, crianças e adolescentes hospitalizados. A opção de Cley, ${ }^{12}$ um dos sujeitos da pesquisa, foi o silêncio. Mas sua expressão facial falava. Os estados afetivos encontram no tônus e na plástica gestual seu canal mais transparente de expressão. A essa linguagem silenciosa do corpo, Wallon (1975) chamou de motricidade expressiva. No trabalho pedagógico em hospital, o professor deve considerar esse tipo de linguagem, devido à sua espontaneidade, como um de seus canais mais importantes de comunicação.

O tema escola aparece, para aqueles que estão hospitalizados, como uma referência à vida normal e saudável e à identidade daqueles que são normais e saudáveis - e, portanto, estão fora do hospital. $\mathrm{Ou}$ seja, não era o conteúdo didático que Cley estava buscando quando pediu um livro de escola, mas sim o reconhecimento de sua auto-estima, presente na figu-

${ }^{12}$ Cley era um menino de 12 anos, internado e reinternado por causa de uma bactéria alojada na virilha. 
ra daquele que é capaz de estudar. Esse desejo e a possibilidade de aprender, ainda que doente, já havia sido acenado por Cley quando ele fez menção ao jogo de xadrez.

O papel da escuta pedagógica aparece como a oportunidade de a criança se expressar verbalmente, e também como a possibilidade da troca de informações, dentro de um diálogo pedagógico contínuo e afetuoso. A relação pedagógica é sempre dialógica, e a escuta pedagógica fez-se presente quando Cley quis compartilhar com a professora as marcas de sua dor, ao contar como ficou doente, quase morreu e foi parar ali.

Mesmo diante das mais inesperadas situações, o bom humor é uma forma de manter aberto o canal de comunicação. Ao relaxar a contração muscular, o riso alimenta emoções propiciadoras de bem-estar físico e emocional.

A escuta pedagógica parece ser o caminho a ser trilhado, pois marca o diálogo não somente como a forma da criança expressar seus sentimentos, mas também organizar suas idéias a partir da linguagem. Além disso, o diálogo pressupõe um outro na relação, que pode trazer informações ou esclarecimentos relevantes que auxiliem o indivíduo a compreender melhor a realidade que o cerca.

Negar-se a desenhar o hospital, como fez Daniel, ${ }^{13}$ não é uma atitude rara na Enfermaria Pediátrica. Embora o desenho seja uma das atividades mais requisitadas pelas crianças na sala de recreação, a maioria delas prefere desenhar qualquer coisa, até mesmo elas próprias jogando o videogame que há nessa sala, do que desenhar a enfermaria pediátrica ou outra parte do HUAP.

Podemos interpretar essa rejeição ao desenho do espaço hospitalar, pelo fato de a criança ver o hospital como espaço e tempo não prazerosos, onde vive momentos tristes e dolorosos de sua vida. Por meio

${ }^{13}$ Daniel era um menino de 13 anos, hospitalizado várias vezes por causa da síndrome nefrótica e de trombose nas veias profundas. do desenho a criança exprime seus sentimentos, cria fantasias e recria realidades. $O$ desenho deve ser analisado, assim, como uma atividade ideográfica na qual a criança trabalha ludicamente sua imaginação e seus desejos.

Em algumas cenas podemos observar também o comportamento do pai de Daniel, que não se contentava com as folhas que possuía para uso pessoal e pedia sempre mais. Essa passagem demonstra a ociosidade dos pais, que também necessitam de um trabalho que ocupe de maneira proveitosa seu tempo no hospital. Outra análise possível dessa situação é a precocidade com que alguns pais são obrigados a deixar a escola para se dedicarem ao trabalho, caso a tenham freqüentado, e, em razão disso, se mostram encantados com os materiais disponíveis na sala de recreação e com a possibilidade de dedicarem seu tempo a uma atividade lúdica ou cultural prazerosa, como o jogo e o desenho, quando passam, então, ainda que por alguns instantes, a ser crianças novamente.

Segundo Wallon (1941), o desenho, que é uma forma de expressão, é revelador de pensamentos, porque também é uma forma de linguagem. Pelo desenho a criança demonstra o conhecimento conceitual que tem da realidade e quais os aspectos mais significativos de sua experiência. Juntamente com o brincar, o desenho é a forma de expressão privilegiada pela criança.

Os momentos de interação com o grupo propiciam à criança oportunidades de desenvolver plenamente sua inteligência. Wallon (1975) alerta-nos que o desenvolvimento da inteligência não se dá isoladamente no interior de organismos individuais, mas está vinculado ao desenvolvimento global do ser humano - social, biológico e afetivo -, em todas as etapas de sua vida.

À medida que as atividades aconteciam, as interações sociais tendiam a se ampliar, tornando-se mais complexas. As crianças passavam a conhecer e a se solidarizar com os companheiros mais constantes. As interações deflagradas pelas atividades em grupo auxiliavam cada criança a compreender melhor o que estava acontecendo com ela e com seus companhei- 
ros, possibilitando uma maior familiaridade com o novo ambiente, que inicialmente lhe era hostil. O colorido e os brinquedos da sala de recreação pareciam exercer um fascínio sobre as crianças, pois todas gostavam de se reunir ali.

Conhecer o significado de suas doenças e também das doenças dos demais companheiros (outras crianças hospitalizadas) pode contribuir não somente para esclarecer quanto à forma de tratamento e profilaxia (se houver) da sua doença, como também contribui para desenvolver um estado de estabilidade emocional, a partir do momento em que a criança ou o adolescente têm conhecimento do que está acontecendo com eles, lidando com seus limites e possibilidades. Além disso, obter informações sobre uma realidade imediata que os atinge concretamente também os auxilia a ampliar um pouco seu conhecimento sobre a vida. É nesse sentido que o desenvolvimento de atividades educativas em hospital contribui, de modo indubitável, para a saúde da criança hospitalizada.

A aquisição de conceitos modifica o processo de percepção da realidade. A formação dos primeiros conceitos relacionados à doença da criança hospitalizada dá-se inicialmente a partir do discurso médico dirigido ao seu acompanhante ou a outro membro da equipe de saúde; é raramente dirigido à própria criança, mas, apesar disso, ela se apropria desse discurso, pois a informação lhe diz respeito.

Quando as crianças são convidadas a se afastarem da sala de recreação para fazer exames, elas deixam de ser crianças e voltam a ser pacientes. Na fala de Kaká, ${ }^{14}$ a sala de recreação apareceu como espaço seguro, como uma referência ao prazer, a um lugar protegido, onde se pode brincar.

\section{Para (não) concluir}

Adoecer faz parte da vida. Todavia, algumas doenças levam à hospitalização, afetando a vida das pessoas

${ }^{14}$ Kaká era uma menina de 7 anos, hospitalizada com endocardite. durante um determinado período de tempo. O caso torna-se mais grave quando o paciente em questão é uma criança e quando a causa de internação, além de ser alguma debilidade física, traz a marca da discriminação socioeconômica de nossa sociedade e, por essa razão, acaba tornando-se crônica, prejudicando uma das etapas mais importantes da vida: a infância.

Ao longo dos seis anos em que venho acompanhando a tentativa de um trabalho pedagógico na Enfermaria Pediátrica do HUAP, percebo que as atividades recreativas que são desenvolvidas oficialmente são esporádicas e atreladas a projetos de extensão e pesquisas que, quase sempre, têm um período de vigência limitado. $\mathrm{O}$ presente trabalho pretende contribuir, assim, para a discussão crítica do lugar da prática pedagógica no hospital.

Neste trabalho percebemos inteligência, emoção e movimento como processos imbricados entre si; assim sendo, o desenvolvimento de um leva, conseqüentemente, ao desenvolvimento dos outros. Isso faz com que "em cada idade ela [a criança] constitua um conjunto indissociável e original” (Wallon, 1941, p. 224). A criança hospitalizada não deixa de ser criança por se tornar paciente. Ela caracteriza-se por intensa atividade emocional, movimento e curiosidade. A educação no hospital precisa garantir a essa criança o direito a uma infância saudável, ainda que associada à doença.

Como a educação pode contribuir para a saúde da criança hospitalizada? Essa foi a questão central que norteou o desenvolvimento do presente estudo. A conclusão a que chego é que a escuta pedagógica atenta e sensível às demandas afetivas, cognitivas, físicas e sociais da criança pode possibilitar a consolidação de sua subjetividade.

O trabalho pedagógico em hospital não possui uma única forma de acontecer. O professor tem de se reconhecer como pesquisador do seu fazer, buscando novas respostas para eternas novas perguntas. Sem pesquisa, será impraticável mover a educação nesse terreno pantanoso, de informações mediáticas e modismos fugazes, em que há tanto tempo tentamos não submergir. 
O materialismo histórico-dialético é uma forma de estudo que busca integrar a atividade científica à ação social. Por isso, não poderia deixar de escolhêlo como princípio filosófico da abordagem teóricometodológica adotada nesta pesquisa, uma vez que a mesma possui como objetivo último transcender a teoria e responder às questões práticas levantadas em campo, como a implantação de um acompanhamento pedagógico sistematizado junto aos co-participantes desta investigação científica.

Constatei que, enquanto professores, precisamos estar atentos para como significamos as ações e atitudes do outro que afetam não só as emoções e visões de mundo, mas também a constituição de si. Wallon (1975, p. 379) lembra-nos que "não há forma de se dirigir à inteligência da criança, sem se dirigir à criança no seu todo". Essa é a proposta da pedagogia hospitalar quando trabalha o sujeito por inteiro e historicamente situado. O conhecimento de seu estado de saúde e do ambiente hospitalar em que se encontra pode alimentar o aspecto positivo da emoção da criança hospitalizada e contribuir para o seu bem-estar físico e psicológico.

Por meio das atividades desenvolvidas junto às crianças hospitalizadas e seus acompanhantes, pude observar as diversas interfaces que a atuação do professor pode assumir numa enfermaria pediátrica. Como ouvinte, o professor trabalha com a emoção e a linguagem, buscando resgatar, através da escuta pedagógica e dialógica, ${ }^{15}$ a auto-estima da criança hospitalizada, muitas vezes suprimida pela enfermidade e pelo sentimento de impotência que pode estar sendo alimentado pela família e pela equipe de saúde. As crianças têm necessidade de falar sobre suas doenças e precisam de alguém que as escute. A linguagem permite, assim, ao ser humano, ultrapassar o concreto e o imediato, fornecendo conteúdos para a refle-

${ }^{15}$ Etimologicamente, a palavra diálogo compõe-se de dois radicais: díade (pelo menos dois) e logus (conhecimento), ou seja, conhecimento que se dá pelo menos entre dois (cf. Vasconcellos, 2002, p. 169). xão consciente, mesmo que posterior à ocorrência dos fatos. Ao lado das palavras, o desenho também constitui um canal de comunicação privilegiado na enfermaria pediátrica.

O papel da educação no hospital e, com ela, o do professor, é propiciar à criança o conhecimento e a compreensão daquele espaço, ressignificando não somente a ele, como a própria criança, sua doença e suas relações nessa nova situação de vida. A escuta pedagógica surge, assim, como uma metodologia educativa própria do que chamamos de pedagogia hospitalar. Seu objetivo é acolher a ansiedade e as dúvidas da criança hospitalizada, criar situações coletivas de reflexão sobre elas, construindo novos conhecimentos que contribuam para uma nova compreensão de sua existência, possibilitando a melhora de seu quadro clínico.

Desse modo, a pedagogia hospitalar deve valorizar o espaço de expressão (coletiva ou individual) e acolhimento das emoções. Entendo que a compreensão das causas que estão na origem da emoção pode contribuir para dissipá-la ou, ao menos, atenuá-la, trazendo bem-estar físico e emocional. Todavia, esse tipo de saber não deve ser exclusivo do domínio infantil. Como professores, também temos de saber lidar com nossas emoções para lidar com as emoções do outro. Temos de respeitar a tristeza e o silêncio da criança hospitalizada. Daí a concepção e a prática de uma escuta pedagógica e de uma educação da emoção, ampliando o conceito de educação atualmente difundido.

Como agenciador de conhecimentos, o professor trabalha com informações, construindo conhecimentos sobre a doença e sua profilaxia, atuando junto às crianças e seus responsáveis e colaborando para a transformação dos conceitos espontâneos em conceitos científicos. O período de hospitalização também pode ser um tempo de aprendizagens que impulsionam o desenvolvimento (Vygotsky, 2000a). Mas a aprendizagem só ocorre se está adequada aos interesses da criança, e todo interesse nasce de uma necessidade. No hospital, a aprendizagem significativa está em conhecer e desvelar o contexto em que a criança se situa, valorizando seus desejos, suas fantasias e 
suas ações, quase sempre desprezados num processo de internação hospitalar. O alargamento do conhecimento é visto como enriquecimento, ampliação da inteligência da pessoa a serviço de si mesma, o que colabora para a tomada de consciência sobre sua realidade imediata.

Com professores no hospital, as crianças hospitalizadas por um longo tempo, ou as que a desejarem, podem ter ainda a oportunidade de trabalhar seus conhecimentos escolares quase que individualmente, como acontece nas classes hospitalares, uma vez que o grupo de crianças é menor do que aquele encontrado nas salas da aula das escolas regulares. Mas não só os conhecimentos escolares devem ser privilegiados. Há no hospital um saber procedimental, que somente a criança que possui uma seringa com medicação intravenosa injetada na superfície de sua mão conhece. Esse conhecimento permite à criança ou ao adolescente a realização de atividades manuais e gráficas, próprias de um acompanhamento pedagógico, sem deixar que a agulha saia da veia, ou que um movimento mais brusco rompa a veia, causando dores e hematomas. As crianças criam, assim, estratégias de sobrevivência a partir dos desafios físicos impostos pela hospitalização.

Como referência à escola, o professor pode tornar-se a ponte, através da realização de atividades pedagógicas e recreativas, com um mundo saudável (a escola) que é levado, pelas próprias crianças, para o interior do hospital como continuidade dos laços de aprendizagem e de vida. Essa idéia de escola que as crianças levam para o universo hospitalar pode ser lida como a representação de um lugar de constituição e referência da identidade de infância.

Durante as interações, o jogo tornou-se o fio condutor de toda a ação pedagógica empreendida junto às crianças e adolescentes hospitalizados. Embora não seja um aspecto predominante da infância, o brinquedo "é um fator muito importante do desenvolvimento" (Vygotsky, 2000a, p. 133), por isso ele foi escolhido como um dos eixos de análise deste trabalho. Ao permitir que a criança reelabore sua realidade $\mathrm{e}$ re(a)presente papéis e ações que não são os seus, a brincadeira e o jogo favorecem a constituição de sua subjetividade. O brinquedo, todavia, não pode ser visto como uma forma de adaptar a criança às condutas médicas e, ainda que o jogo busque ocupar o tempo ocioso do hospital, o objetivo de uma prática pedagógica é transformar esses momentos também em tempo de aprendizagens. Pois entendo que a criança, porque aprende, também se desenvolve, e isso a ajuda a enfrentar melhor os acontecimentos de sua vida.

A composição e recomposição dos grupos de brincadeira produziram efeitos na organização da rotina médica hospitalar porque se apropriaram de um espaço físico e psicológico, ressignificando o sentido da hospitalização para as crianças e seus acompanhantes, favorecendo a (re)invenção de outras formas de apropriação de seu funcionamento. Se no início as crianças tinham sua subjetividade diluída na rotina hospitalar, com o tempo elas tornaram-se protagonistas de suas próprias ações.

Assim, no decorrer do acompanhamento pedagógico constatou-se, com gestos, palavras e comportamentos, sensíveis modificações na forma como as crianças reagiam à hospitalização e à doença. Os resultados que esta pesquisa aponta levam-me a compreender que o papel da educação junto à criança hospitalizada é resgatar sua subjetividade, ressignificando o espaço hospitalar através da linguagem, do afeto e das interações sociais que o professor pode propiciar. Portanto, é possível pensar o hospital como um espaço de educação para as crianças internadas. Mais do que isso, é possível pensá-lo como um lugar de encontros e transformações, tornando-o um ambiente propício ao desenvolvimento integral da criança.

Enxergar e acreditar na criança enferma, assim como em qualquer criança, é um primeiro passo para compreendê-la, respeitá-la e auxiliá-la em seu processo de desenvolvimento, porque "a criança não sabe senão viver sua infância. Conhecê-la pertence ao adulto" (Wallon, 1941, p. 11).

REJANE DE SOUZA FONTES, mestre em educação pela Universidade Federal Fluminense (UFF) e doutoranda em educação pela Universidade do Estado do Rio de Janeiro, é professora 
na Faculdade de Educação na UFF. Entre os seus artigos publicados, destacam-se: Educación hospitalaria: um recurso frente al rezago escolar (Revista Latinoamericana de Estudios Educativos, Cidade do México, v. 33, nº 1, 2003, p. 151-160); A classe hospitalar e a inclusão da criança enferma na sala de aula regular (Revista Brasileira de Educação Especial, Marília, v. 8, n 1, 2002, p. 45-54) e Educação Especial: um capítulo à parte na história do direito à educação no Brasil (Ensaio: Avaliação e Políticas Públicas em Educação, Rio de Janeiro, v. 10, n 37, 2002, p. 503526). Participa do grupo de pesquisa "Inclusão escolar de alunos com deficiências no ensino regular - práticas pedagógicas e cultura escolar", coordenado pela professora Rosana Glat. E-mail: rejanefontes@ig.com.br

\section{Referências bibliográficas}

AJURIAGUERRA, Julian de, (1980). Manual de psiquiatria infantil. Rio de Janeiro: Masson do Brasil. Título original: Manuel de psychiatrie de l'enfant.

ANGERAMI-CAMON, Valdemar Augusto, (1988). A psicologia no hospital. São Paulo: Traço.

ARIÈS, Philippe, (1977). História da morte no Ocidente: da Idade Média aos nossos dias. Rio de Janeiro: Francisco Alves. , (1981). História social da criança e da família. Rio de Janeiro: Zahar.

, (1982). O homem diante da morte - v. 2. Rio de Janeiro: Francisco Alves.

BARBIER, René, (1985). A pesquisa-ação na instituição educativa. Rio de Janeiro: Jorge Zahar.

, (2002). A pesquisa-ação. Brasília: Plano Editora (série Pesquisa em Educação, v. 3).

BOGDAN, Roberto C., BIKLEN, Sari Knopp, (1994). Investigação qualitativa em educação: uma introdução à teoria e aos métodos. Portugal: Porto Editora.

BRASIL, (1977). Ministério da Saúde. Definições e Normas das instituições e serviços de saúde. Diário Oficial da União de 5/4/1977 - Seção I, Parte I, p. 3929.

, (1994). Ministério da Educação e do Desporto. Secretaria de Educação Especial. Política Nacional de Educação Especial. Brasília, DF (Mensagem especial, v. 1).

, (1997). Conselho Nacional de Saúde (CNS)/Ministério da Saúde. Legislação e normas regulamentadoras de pesquisa envolvendo seres humanos. Brasília: CNS, de 10 de outubro de 1996, publicada em abril de 1997.
, (2001). Resolução CNE/CEB nº 2, de 11 de setembro de 2001. Estabelece as Diretrizes Nacionais de Educação Especial. Diário Oficial [da] República Federativa do Brasil. Brasília, DF.

CECCIM, Ricardo Burg, (1997). Criança hospitalizada: a atenção integral como uma escuta à vida. In: CECCIM, Ricardo Burg, CARVALHO, Paulo R. Antonacci (orgs.). Criança hospitalizada: atenção integral como escuta à vida. Porto Alegre: Editora da UFRGS, p. 27-41.

CECCIM, Ricardo Burg, CARVALHO, Paulo R. Antonacci, (orgs.) (1997). Criança hospitalizada: atenção integral como escuta à vida. Porto Alegre: Editora da UFRGS.

CECCIM, Ricardo B., FONSECA, Eneida S., (1999). Classe hospitalar: buscando padrões referenciais de atendimento pedagógico-educacional a criança e ao adolescente hospitalizados. Revista Integração, MEC/SEESP, ano 9, n 21, p. 31-39.

CHIATTONE, H. B. C., (1984). Relato de experiências de intervenção psicológica junto à criança hospitalizada. In: ANGERAMI-CAMON, V. A. (org.). Psicologia hospitalar: teoria e prática. São Paulo: Traço, p. 40-132.

FAZENDA, Ivani, (1989). Metodologia da pesquisa educacional. São Paulo: Cortez.

FONSECA, Eneida Simões da, (2001). Atendimento escolar hospitalar: o trabalho pedagógico-educacional no ambiente hospitalar: a criança doente também estuda e aprende. Rio de Janeiro: UERJ.

, (2002) Aspectos da ecologia da classe hospitalar no Brasil. Disponível em: <http://www.educacaoonline.pro.br/ aspectos_da_ecologia.asp?f_id_artigo=178/>. Acesso em: 19 fev.

FONTES, Rejane de S., (1998). Classe hospitalar: a validade de uma alternativa educacional a curto prazo. Monografia de Graduação da Faculdade de Educação da Universidade Federal Fluminense.

GUIMARÃES, S. S., (1988). A hospitalização na infância. Psicologia, Teoria e Pesquisa, Brasília, v. 4, no 2, p. 102-112.

KAMIYAMA, Y., (1972). O doente hospitalizado e sua percepção quanto à prioridade de seus problemas. Tese de doutorado. Faculdade de Psicologia da Universidade de São Paulo.

LENZI, T., (1992). Recreação para crianças em enfermaria pediátrica. In: FRIEDMANN, A., MICHELET, A., LENZI, T. et al. $O$ direito de brincar: a brinquedoteca. São Paulo: Scritta, p. 136-145.

LIBÂNEO, José Carlos, (2000). Pedagogia e pedagogos, para $q u \hat{e}$ ? São Paulo: Cortez. 
LINDQUIST, J., (1993). A criança no hospital: terapia pelo brinquedo. São Paulo: Página Aberta.

LISPECTOR, Clarice, (1978). Um sopro de vida. Rio de Janeiro: Nova Fronteira.

LUCKESI, Cipriano Carlos, (1994). Filosofia da educação. São Paulo: Cortez.

LÜDKE, Menga, ANDRÉ, Marli E. D. A., (1986). Pesquisa em educação: abordagens qualitativas. São Paulo: EPU.

MANNONI, M., (1983). A criança, sua doença e os outros. $3^{\mathrm{a}} \mathrm{ed}$. Rio de Janeiro: Zahar. Tradução de A. C. Vilaça.

MONTEIRO, Roberto Alves, (1998). Pesquisa em educação: alguns desafios da abordagem qualitativa. In: MONTEIRO, Roberto Alves. Fazendo e aprendendo pesquisa qualitativa em educação. Juiz de Fora: FEME/UFJF, p. 7-22.

NOVA Enciclopédia Ilustrada Folha, (1996). São Paulo: Folha da Manhã (Folha de S.Paulo).

PAULA, Ercília Maria Angeli Teixeira de, (2002). Crianças e professores em hospitais: aprendizes especiais na diversidade dos contextos hospitalares. In: ENCONTRO NACIONAL DE DIDÁTICA E PRÁTICA DE ENSINO, 11., 2002. Anais..., 1 CD-ROM.

RAIMBAULT, Ginette, (1979). A criança e a morte: crianças doentes falam da morte: problemas da clínica do luto. Rio de Janeiro: Francisco Alves.

SANTA ROZA, Eliza, (1993). Quando brincar é dizer. Rio Grande do Sul: Relume Dumará.

SOARES, José Luís, (1982). Ciência: o corpo humano. São Paulo: Moderna.

SPITZ, Renee, (1965). O primeiro ano de vida. São Paulo: Martins Fontes.

TAAM, Regina, (1997). Educação em enfermarias pediátricas. Ciência Hoje, Rio de Janeiro, v. 23, nº 133, p. 74-75. , (2000). Assistência pedagógica à criança hospitali- zada. Tese de doutorado. Faculdade de Educação da Universidade Federal Fluminense.

THIOLLENT, Michel, (1985). Metodologia da pesquisa-ação. São Paulo: Cortez.

TRIVIÑOS, Augusto Nibaldo Silva, (1987). Introdução à pesquisa em ciências sociais: a pesquisa qualitativa em educação. São Paulo: Atlas.

VASCONCELLOS, Vera Maria Ramos de, (2002). Construção da subjetividade: processo de inserção de crianças pequenas e suas famílias à creche. Tese apresentada no Concurso Público para Professor Titular em Educação Infantil da Faculdade de Educação da Universidade do Estado do Rio de Janeiro.

VYGOTSKY, Lev S., (2000a). A formação social da mente: o desenvolvimento dos processos psicológicos superiores. São Paulo: Martins Fontes. Tradução de José Cipolla Neto, Luiz Silveira Menna Barreto e Solange Castro Afeche. , (2000b). Pensamento e linguagem. São Paulo: Martins Fontes.

, (2000c). Manuscrito de 1929: psicologia concreta do homem. $2^{\text {a }}$ ed. Educação \& Sociedade, Campinas, v. 21, $\mathrm{n}^{\mathrm{o}} 71$, p. 21-44, out.

WALLON, Henri, (1971). As origens do caráter na criança: os prelúdios do sentimento de personalidade. São Paulo: Difusão Européia do Livro. , (1941). A evolução psicológica da criança. Rio de Janeiro: Andes.

, (1975). Psicologia e educação da infância. Lisboa: Estampa.

WELLER, Waldemar, (1979). A saúde da criança. Rio de Janeiro: Civilização Brasileira. 


\section{Resumos/Abstracts}

Rejane de S. Fontes

A escuta pedagógica à criança hospitalizada: discutindo o papel da educação no hospital

Busca compreender o papel da educação para a saúde da criança hospitalizada em enfermarias pediátricas, analisando a ação do professor em um hospital público (Hospital Universitário Antônio Pedro - Niterói, RJ). A questão central que norteou o desenvolvimento da pesquisa foi: Como a educação pode contribuir para a saúde da criança hospitalizada? Utilizou-se metodologia a observação participante de situações da interação criança/criança, criança/adulto e criança/meio. As categorias de análise foram: linguagem, brinquedo, emoção e conhecimento, apoiadas nos referenciais teóricos propostos por Wallon e Vygotsky. A conclusão foi que a educação possibilita à criança ressignificar sua vida e o espaço hospitalar no qual se encontra. Com base em uma escuta pedagógica atenta e sensível, pode-se colaborar para o resgate da subjetividade e da auto-estima infantis, contribuindo para o bemestar e a saúde da criança hospitalizada. A pesquisa revelou que são grandes as possibilidades de ação do professor nesse novo espaço de atuação; no entanto, também é grande o desafio de construir uma prática educativa diferenciada da que ocorre na instituição escolar, requerendo princípios específicos e outros níveis de conhecimento que respaldem o complexo trabalho pedagógico no campo hospitalar.

Palavras-chave: educação; saúde; pedagogia hospitalar; subjetividade

\section{Pedagogical "listening" and the hospitalised child: a discussion of the role of education in hospital}

The aim of this study is to understand the role of education in the health of the hospitalised child, by means of an analysis of the teacher's activity in a public hospital (The Antônio Pedro University Hospital - Niterói, RJ). The central question which guided the development of the research, based upon participant observation of situations which involved interaction between children, children and adults and between children and the environment, was: How can education contribute to the health of the hospitalised child? The categories of analysis employed were: language, toys, emotion and knowledge, based upon theoretical references proposed by Wallon and Vygotsky. The conclusions suggest that education helps the child to re-signify his/her life in the hospital environment and that an attentive and sensitive pedagogical 'listening' can help to rescue the subjectivity and self-esteem of hospitalised children, and contribute to their well-being and health. The research reveals that the possibilities of action for the teacher in this new environment are great; nevertheless, the challenge of constructing a different educational practice to that which takes place in the school institution is great and demands specific principles and other levels of knowledge that lend support to this complex pedagogical work in the hospital field.

Key-words: education; health; hospital pedagogy; subjectivity 